\title{
Cigarette sources for teens by grade: Implications for prevention and intervention
}

\author{
Netra M. Thakur \\ Thomas Jefferson University Hospital \\ Michael P. Rosenthal \\ Thomas Jefferson University Hospital \\ Priscilla Latta \\ Jefferson Medical College \\ Jamie L. Robinson \\ Jefferson Medical College \\ James Diamond

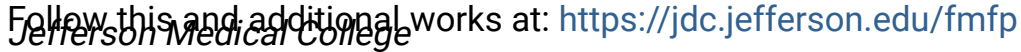 \\ Part of the Family Medicine Commons, and the Translational Medical Research Commons \\ Let us know how access to this document benefits you
}

\section{Recommended Citation}

Thakur, Netra M.; Rosenthal, Michael P.; Latta, Priscilla; Robinson, Jamie L.; and Diamond, James, "Cigarette sources for teens by grade: Implications for prevention and intervention" (2001). Department of Family \& Community Medicine Faculty Papers. Paper 1.

https://jdc.jefferson.edu/fmfp/1

This Article is brought to you for free and open access by the Jefferson Digital Commons. The Jefferson Digital Commons is a service of Thomas Jefferson University's Center for Teaching and Learning (CTL). The Commons is a showcase for Jefferson books and journals, peer-reviewed scholarly publications, unique historical collections from the University archives, and teaching tools. The Jefferson Digital Commons allows researchers and interested readers anywhere in the world to learn about and keep up to date with Jefferson scholarship. This article has been accepted for inclusion in Department of Family \& Community Medicine Faculty Papers by an authorized administrator of the Jefferson Digital Commons. For more information, please contact: JeffersonDigitalCommons@jefferson.edu. 
The Internet Journal of Family Practice $^{\text {TM }}$

\title{
Cigarette Sources For Teens By Grade: Implications For Prevention And Intervention
}

\author{
Netra M. Thakur MD MPH \\ Clinical Assistant Professor \\ Department of Family Medicine \\ Thomas Jefferson University Hospital \\ Michael P. Rosenthal MD \\ Clinical Professor and Director, Section of Community Health \\ Department of Family Medicine \\ Thomas Jefferson University Hospital \\ Priscilla Latta \\ Class of 2002 \\ Jefferson Medical College \\ Jamie L. Robinson MS \\ Jefferson Medical College \\ James J. Diamond PhD 9 \\ Director, Greenfield Research Center \\ Department of Family Medicine \\ Thomas Jefferson University Hospital
}

\section{Citation:}

Netra M. Thakur, Michael P. Rosenthal, Priscilla Latta, Jamie L. Robinson \& James J. Diamond: Cigarette Sources For Teens By Grade: Implications For Prevention And Intervention: The Internet Journal of Family Practice. 2001; Volume 2, Number 1. 


\section{Abstract}

ABSTRACT Objective: To identify at-risk teen populations and their sources of cigarettes, in order to help target future efforts in prevention of teen smoking. Methods: Analysis of smoking behavior questions for students in grades 6, 7, 9 and 12 from the 1997 Pennsylvania Biennial Youth Risk Survey. Results: Current smoking prevalence was $20.9 \%$ overall. The number of ninth grade smokers was almost five times higher than the number of sixth grade smokers (30.6\% vs. 6.6\%). Seventy-three percent of the teens identified friends as a source of tobacco. Stores became the most common source for twelfth graders only. Conclusion: Teenage smoking remains a serious public health concern and easy access to tobacco persists, despite recent legislation. The significant increase in smoking between 6th and 9th graders and the high social availability of cigarettes demonstrate the need for continued attempts to limit teen's access to tobacco and emphasis on prevention efforts in younger adolescents.

\section{BACKGROUND}

Tobacco use is the most important preventable cause of illness and death in the United States. ${ }^{1}$ Notably, adolescence is the critical period during which most people begin smoking. ${ }^{2},{ }^{3}$ Despite the known health hazards of smoking, almost 3000 adolescents become new smokers every day. ${ }^{4}$ Extrapolating from these patterns, the Centers for Disease Control and Prevention (CDC) estimates that 5 million individuals who were 0 17 years of age in 1995 will die prematurely from a smoking-related illness. ${ }_{-}^{5}$

Although teen smoking is a known national public health concern, teens continue to access tobacco freely.3 In 1993, University of Michigan's Monitoring the Future Project found that $75 \%$ of eighth graders and $89 \%$ of tenth graders surveyed reported easy access to cigarettes. ${ }^{6}$ Similarly, CDC data from the Youth Risk Behavior Survey (YRBS) show that $38.7 \%$ of high school students aged 17 years or younger were able to get cigarettes from a store._B By 1999, tobacco consumption by teens aged 12 to 17 years generated over $\$ 1$ billion in annual revenue. ${ }_{-}^{8}$

Accordingly, one approach to the prevention and control of teen smoking is to restrict illegal sales of tobacco products to minors. Other approaches to restrict tobacco access have included smoke-free indoor air-restrictions and heavy excise taxes. ${ }^{9}$ Efforts to reduce teens' access to tobacco have since proliferated. In August 1996, the FDA issued regulations to restrict the sale, distribution, promotion and advertising of tobacco-related products to anyone under the age of eighteen. ${ }^{10}$ The Synar legislation, promoted by the Substance Abuse and Mental Health Services Administration, restricts block grant funding for substance abuse programs from states unable to show compliance with the FDA regulations.10 As a result, all states have laws prohibiting the sale of tobacco products to minors. Unfortunately, enforcement efforts have been variable because of limited community resources and commitment. ${ }^{11}$ A 1995 survey by the Department of 
Health and Human Services found that $56 \%$ of states reported no statewide enforcement activity, and another $24 \%$ reported that their main enforcement activity consists of vendor compliance checks only. ${ }^{12}$ More recently, The Master Settlement Agreement between the states and the tobacco industry has since allowed states to develop tobacco use prevention and reduction programs. 13

Even after intensive enforcement of local youth tobacco access laws, however, some data have shown that teen smoking rates remained unchanged. ${ }^{14}$ Multiple broad cultural forces challenge the efforts to stop teens from using tobacco. ${ }_{15}$ The influence of peer pressure, the glamorized images of tobacco in the media, the tobacco industry's marketing strategies, and the lassitude of many cigarette vendors are just some of the many factors that perpetuate teen smoking.2,3,10,15

Not surprisingly, during the 1990s the incidence of teen smoking increased. Results of the CDC 1997 Youth Risk Behavior Survey indicated that the prevalence of current smoking among US teens rose from $27.5 \%$ in 1991 to $36.4 \%$ in $1997 .{ }^{16}$ Over $40 \%$ of 16,000 high school students reported use of a tobacco product during the prior month.

The following study examines data from Pennsylvania Biennial Youth-Risk Survey regarding the prevalence of cigarette smoking and sources of cigarettes among teenagers. The Pennsylvania Commission on Crime and Delinquency and the Governor's Policy Council sponsored this survey, with funding assistance from the Drug Free Schools and Communities Act. The objectives of this study are to identify at-riskeen populations and their sources of cigarettes, in order to help target future efforts in prevention of teen smoking.

\section{METHODS}

The survey instrument, The Primary Prevention Awareness Attitude and Usage Scale (PPAUS), has been distributed each spring in odd-numbered years since 1989 and has proven to be a reliable and valid tool. ${ }^{17}$ Working with the Health Promotion Council of Southeastern Pennsylvania, a community based non-profit organization with programs for tobacco control, we focused on Region One of this Pennsylvania survey. This region, including Philadelphia and its four contiguous counties (Bucks, Chester, Delaware and Montgomery), is comprised of urban, suburban and rural communities, and represents a heterogeneous population.

In 1997, the total survey population consisted of a stratified random sample of $20 \%$ of public school students and 10\% of non-public school students in grades 6,7,9 and 12 throughout Pennsylvania. This descriptive study evaluated 1997 data regarding tobacco use patterns among teens in the Southeastern Pennsylvania. Diagnostics Plus, an independent organization, initially compiled the raw data which were further analyzed using the Statistical Analysis Software (SAS) program. 
Key questions from the database were selected. The first question was "How often do you use (or have you ever used) cigarettes?" Responses were categorized to "Non-Use", "Ever Use" (not in the past year), "Occasional use" (1-2 times a year), and "Current Use" (1-2 times a month, 1-2 times a week, daily use). This categorization reflects the definitions used in the CDC's database on teen smoking behaviors. ${ }^{18}$ The second question, "From which people or places did you get cigarettes?" was used to identify supply sources. Students could identify multiple sources for cigarette access. The most frequent responses were used in further data analysis.

\section{RESULTS}

There were 25,021 surveys returned for Southeastern Pennsylvania (Region 1). Due to missing data, 1,677 (6.7\%) surveys were removed, leaving a study sample of 23,334 (Table 1). The overall response rate could not be calculated because the administering group, Diagnostics Plus Inc., had no school enrollment records or absentee data. The study sample population does reflect the population of Southeastern Pennsylvania, based on estimates from 1990 US Census Data19. More than one fifth (20.9\%) of this teen population were current smokers (smoked at least once a month) (Figure 1). The prevalence of smoking among ninth graders was almost five times as high as the prevalence in sixth graders (30.6\% vs. 6.6\%) and more than twice as high as that for seventh graders $(14.9 \%)$.

In general, whites had a higher prevalence of smoking than non-whites. White females in both suburban and urban counties had the highest prevalence of smoking overall. Fortynine percent of white 12 th grade females smoked compared with $21 \%$ of the non-white female 12th graders. Prevalence of smoking for grade, gender and race were similar for both urban Philadelphia County and the surrounding suburban counties.

Thirty-nine percent of the total current smokers purchased cigarettes from vending machines. Sixty-two percent bought cigarettes from a store. Twenty-five percent accessed cigarettes from a family member. Seventy-three percent admitted to getting cigarettes from a friend, the most common source of cigarettes for current smokers (Figure 2). The teens that chose their friends as a source of cigarettes did not appreciably differ by gender, race, grade or urban/suburban location. Twelfth graders used friends as a source less often $(61.9 \%)$ than their younger peers $(74.9 \%)$.

While friends remained the consistent suppliers of cigarettes for all grade levels, stores became a more important source for the older teens. Eighty-eight percent of twelfth graders and $64.9 \%$ of ninth grade current smokers listed stores as a source of cigarettes as compared to $35.7 \%$ and $22 \%$ of sixth graders. Twenty-five percent of the entire population received cigarettes from family members. This percentage was similar among all grades. Youth less than 18 years in Philadelphia county were more likely to obtain cigarettes from a store ( $70 \%$ female and $73 \%$ male), than their suburban counterparts (48\% female and 51\% male). Aside from this difference in store access between 
Philadelphia and the suburban communities, the teens' sources of cigarettes were otherwise similar throughout the region.

\section{DISCUSSION}

This study examines the critical issue of sources of cigarettes for various age groups. The results of this report identify a high rate of smoking in a heterogeneous population of diverse ethnic backgrounds and economic status. ${ }_{19}^{19}$ The prevalence estimates are based upon self-report, which has been previously shown to correlate with biochemical markers. ${ }^{20},{ }^{21}$ The smoking prevalence identified for this region reflects rates shown in a national survey of similarly aged teens. ${ }^{22}$ Overall, in this population, smoking prevalence was much higher for ninth and twelfth grade students than for the sixth and seventh graders.

It is estimated that $90 \%$ of all tobacco use initiation occurs in persons less than 18 years of age 3 and the results imply that, in particular, the most vulnerable time for teens is early adolescence. Because the increase in smoking behavior is greatest at that time, young teens should be specifically targeted for prevention efforts. School-based interventions may provide the best forum for effective smoking education and prevention programs.3, ${ }_{23}{ }_{24}$ In the mid 1980s, for instance, the National Cancer Institute and the National Heart Lung and Blood Institute supported trials to investigate the best method for schools to prevent tobacco use. They concluded that school-based smoking prevention programs were effective in delaying the onset of tobacco use.23 In 1994, the CDC recommended intensive smoking education for students in grades 6 through 8. Studies have shown that didactic sessions, refusal skills training and health awareness counseling, particularly when peer-led, are all effective in delaying the onset of smoking.3,13,16,23

The majority of teens responding to this survey readily obtained cigarettes from each other and also reported liberal opportunity to purchase tobacco from vendors. Notably, teens in the sixth grade were more likely to obtain cigarettes from their friends while the 12 th graders more likely obtained cigarettes at a store. The high percentage $(88 \%)$ of older teen smokers purchasing cigarettes from stores indicates the widespread availability of cigarettes among teens.

Older teens' easy access to cigarettes inevitably trickles down to the younger teens that primarily obtain cigarettes from their friends. Successful tobacco-use prevention programs for youth must address the provision of cigarettes to each other. Curbing illegal tobacco sales to teens, and also developing school-based and public education initiatives could effectively discourage social availability of tobacco to youth.8,13,24 This study identifies peer-related phenomena that support the need for comprehensive, youth-led programs that use multiple approaches to teen smoking prevention and intervention. A stronger prevention emphasis on young teen populations is required in order to halt the growing epidemic of teen smoking. 


\section{References}

1. US Preventive Services Task Force. Guide to Clinical Preventive Services 2nd Edition. Williams and Wilkins, 1997.

2. Nelson D; Giovino GA, Shopland DR, Mowery PD, Mills SL, Eriksen MP. Trends in Cigarette Smoking Among US Adolescents 1974-1991. American Journal of Public Health. Jan 1995;85: 34-40.

3. Preventing Tobacco Use Among Young People: A Report of The Surgeon General. Atlanta, GA: US Department of Health and Human Services.1994.

4. Jason LA, Ji YP, Anes MD, Birkhead SH. Active Enforcement of Cigarette Control Laws in the Prevention of Cigarette Sales to Minors. JAMA. 1991; 266: 3159-3161.

5. Centers for Disease Control and Prevention. Projected Smoking-Related Deaths Among Youth - United States. MMWR.1996;45: 971-974.

6 Lynch BS, Bonnie RJ, eds. Growing Up Tobacco Free. Preventing Nicotine Addiction in Children and Youths. NA Press, Washington DC 1994.

7. Centers for Disease Control and Prevention. Tobacco Use and Usual Source of Cigarettes Among High School Students - United States, 1995. MMWR. 1996;45:413418.

8. Clark PI, Natanblut SL, Schmitt CL, Wolters C, Iachan R. Factors Associated With Tobacco Sales to Minors: Lessons Learned From the FDA Compliance Checks. JAMA. 2000;284:729-734.

9. Centers for Disease Control and Prevention. State Laws and Tobacco Control. MMWR.1995;44: 55-56.

10. Gostin LO, Arno PS, Brandt AM. et al. FDA Regulation of Tobacco Advertising and Youth Smoking: Historical, Social and Constitutional Perspectives. JAMA. 1995; 225:410-418.

11. Cummings KM, Hyland A, Saunders-Martin T, Perla J, Coppola PR, Pechacek TF. Evaluation of an Enforcement Program to Reduce Tobacco Sales to Minors. American Journal of Public Health. 1998; 88:932-936.

12. Voorhees CC, Swank RT, Stillman FA, Harris DX, Watson HW,Becker DM. Cigarette Sales to African-American and White Minors in Low-Income Areas of Baltimore. American Journal of Public Health. 1997:87:652-654. 
13. Bauer UE, Johnson TM, Hopkins RS, Brooks RC. Changes in Youth Cigarette Use and Intentions Following Implementation of a Tobacco Control Program: Findings From the Florida Youth Tobacco Survey, 1998-2000. JAMA. 2000;284:723-728.

14. Rigotti NA, DiFranza JR,Chang Y, Tisdale T, Kemp B, Singer, DE. The Effect of Enforcing Tobacco Sales Laws on Adolescents Access to Tobacco and Smoking Behavior. NEJM. 1997; 337:1044-1051.

15. An LC, O'Malley PM, Schuenberg JE, Bachman, JG, Johnson LD. Changes in the High End of Risk in Cigarette Smoking Among US High School Seniors, 1976-1995. American Journal of Public Health. 1999;89:699-705.

16. Centers for Disease Control and Prevention. Tobacco Use Among High School Students. MMWR. 1998;47:229-233.

17. A Generation At Risk - Alcohol, Tobacco, Other Drugs, Weapons, Violence, and Pennsylvania Youth. The 1997 Survey; Diagnostics Plus, Sate College, Pennsylvania.

18. Centers for Disease Control and Prevention. Youth Risk Behavior Surveillance -United States, 1997 MMWR. 1998;47:1-89.

19. 1990 US Census Data. http://www.venus.census.gov

20. Abrams K, Skolnik N, Diamond JJ. Patterns and Correlates of Tobacco Use Among Suburban Philadelphia 6th -12th grade students. Family Medicine. 2/1999; 31: 128-132.

21. Luepker RV, Pallonen UE, Murray PM, Pririe PL. Validity of telephone surveys in assessing cigarette smoking in young adults. American Journal of Public Health. 1989;79:202-204.

22. Centers for Disease Control and Prevention. Tobacco Use Among Middle and High School Students - United States, 1999. MMWR. 2000;49:49-53.

23. Epps RP, Manley MW , Glynn TJ. Tobacco Use Among Adolescents: Strategies for Prevention. Pediatric Clinics of North America. 1995;42:389-402.

24. Forster JL, Murray DM, Wolfson M, Blaine T, Wagenaar A, Henrikus D. Effects of Community Policies to Reduce Youth Access to Tobacco. American Journal of Public Health.1998;88:1193-1198. 